\title{
Arsenic [As (III)] Removal Using Almond Shells
}

\author{
Deekshitha $S \mathbf{J}^{1}$, Kavya $M^{1}$, Pooja $S P^{1}$, Nandini $C^{1}$, Shilpa B $S^{2}$ \\ ${ }^{1}$ Project Associates, ${ }^{2 *}$ Associate Professor \\ ${ }^{1}$ Department of Environmental Engg., Vidyavardhaka College of Engg., Mysuru-02 \\ ${ }^{2}$ Department of Civil Engineering, Vidyavardhaka College of Engineering, Mysuru-02 \\ shilpa.bs@vvce.ac.in
}

\begin{abstract}
Contamination of groundwater by Arsenic poses severe health hazard problem. As trivalent Arsenic ion (Arsenite) is more toxic than pentavalent ion (Arsenate), present work focuses on removal of Arsenite using dry Prunus Amygdalus (Almond) shells as adsorbent. In this work, pyrolysed and non-pyrolysed shells of particle size $1.18 \mathrm{~mm}$ are used in batch process. The uptake capacity of the present adsorbent was studied as a function of $\mathrm{pH}$, adsorbent dosage and contact time. For pyrolysed and non-pyrolysed, Optimum $\mathrm{pH}$ was found to be 4 and 5 respectively. Effective dosage of pyrolysed and non-pyrolysed shells was found to be 2 and $2.2 \mathrm{~g} / \mathrm{L}$ respectively and optimum contact time for pyrolysed and non-pyrolysed shellswas found to be 30 minutes and 25 minutes respectively for Synthetic solution. The optimum conditions were considered to treat the hair dye solution for Arsenic removal. The result proves that the Almond shells are effective adsorbent in Arsenic removal.
\end{abstract}

Keywords: Arsenic, Almond Shells, Pyrolysed, Non-pyrolysed and Hair Dye

\section{INTRODUCTION}

Arsenic is recognized as a poison and cancer causing substance. It occurs in different forms as pentavalent and trivalent arsenic, where pentavalent is more toxic than trivalent. In water, arsenic has no smell or taste and can only be detected through a chemical test. According to Indian Standard Specifications for drinking water IS: 10500, 1991 desirable limit for arsenic is $0.05 \mathrm{mg} / \mathrm{L}$. Beyond this, the water is not fit for domestic use. In Indian Scenario, Investigations by Central Groundwater Board reveals that arsenic contamination $(>0.05 \mathrm{mg} / \mathrm{L})$ is affecting the states of West Bengal, Bihar, Uttar Pradesh, Assam, Chhattisgarh. The Bengal Delta Plain covering Bangladesh and West Bengal in India is the most severe case of groundwater arsenic contamination. Besides this, high arsenic groundwater has also been reported from Jharkhand and Manipur state. The most common sources of elevated arsenic levels in groundwater are weathering of arsenic bearing minerals and ores, Infiltration or runoff from locations of past mining activities. The literature collected shows that many works has been carried out on Arsenic removal using different adsorbents. But, no work has been carried out for Arsenic removal using almond shells. Keeping the above facts in view, an attempt is made in this research work to remove the Arsenic using almond shells. The objective is to know the feasibility of almond shells in arsenic removal.

\section{Materials And Methodology}

\subsection{Almond Shells}

In this work, Almond shells are used as adsorbent. Almond nuts are procured from local stores of Mysuru and the almond nuts were crushed using wooden mallet and the shells were collected.

\subsection{Preparation of Almond Shells as Adsorbent}

\subsubsection{Preparation of non-pyrolyzed almond shells}

Almond shells were grinded using mixi (konika, 500w) for 5 minutes and the grinded Almond shells are sieved manually to get a particle of size $1.18 \mathrm{~mm}$. Plate 1 shows the flow sheet of non-pyrolysed Almond shells. 


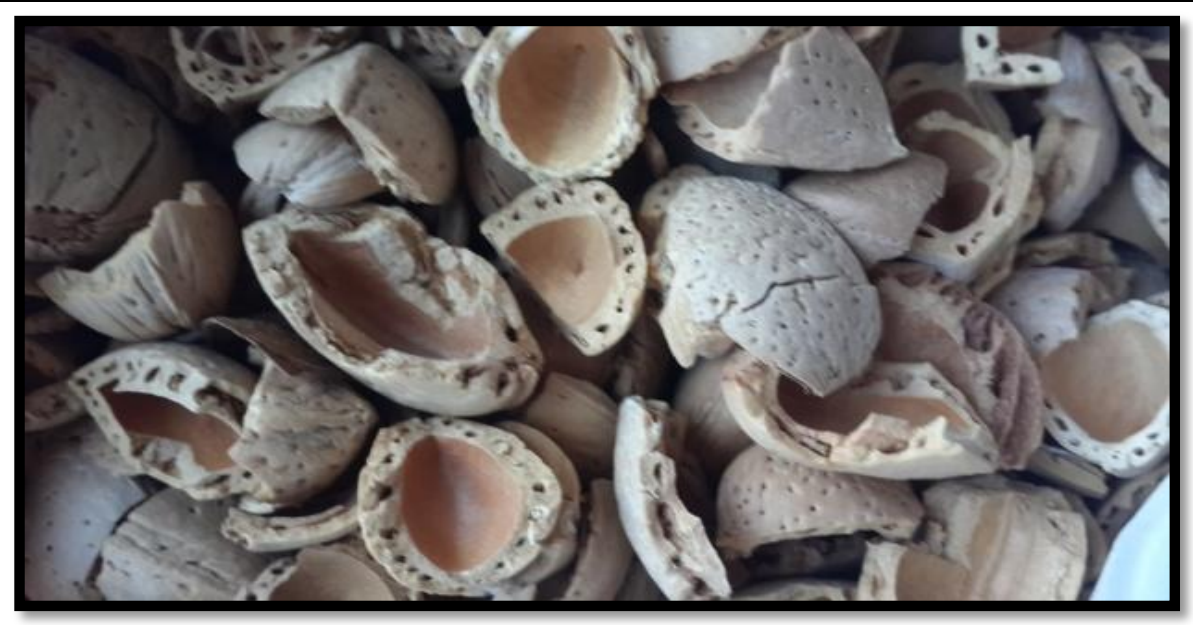

Plate1. Almond shells

\subsubsection{Preparation of pyrolyzed almond shells}

Almond shells were grinded using mixi (Konika, 500w) for 5 minutes and the grinded Almond shells are filled in mud pot and sealed with mud for air tight and kept in muffle furnace for about 2 hours at $500^{\circ} \mathrm{C}$ for pyrolysis. After pyrolysis, the mud pots were removed and the pyrolyzed Almond shells are seived manually to get a particle of size $1.18 \mathrm{~mm}$. Plate 2 shows the flow sheet of pyrolysed Almond shells.

\subsection{Arsenic Determination}

Determination of Arsenic is done by standard method i.e., Spectrophotometric method in which Spectrophotometer (Systronics) is used and the absorbance is measured at $556 \mathrm{~nm}$ against the corresponding reagent blank. The chemicals used are Potassium iodate, Hydrochloric acid, Variamine blue B solution and Sodium acetate.

\subsubsection{Preparation of standard series}

Pipette out 1, 2, 3, 4, 5 and $6 \mathrm{ml}$ of standard Arsenic solution into nessler's tube and add $1 \mathrm{ml}$ of potassium iodate, $1 \mathrm{ml}$ of hydrochloric acid, $1 \mathrm{ml}$ of variamine blue b solution and $2 \mathrm{ml}$ of sodium acetate solution and make up it with distilled water. After $5 \mathrm{~min}$, Measure the absorbance using spectrophotometer at $556 \mathrm{~nm}$ and note down the absorbance to prepare a graph of concentration of Arsenic v/s absorbance.

\subsection{Determination of Optimum pH for Pyrolyzed and Non- Pyrolyzed Almond Shells}

In order to find the optimum $\mathrm{pH}$, the synthetic Arsenic solution having concentration of $0.5 \mathrm{mg} / \mathrm{L}$ was used, this solution was taken in 1 liter beakers and the $\mathrm{pH}$ of the solution was varied from 2, 3, 4, 5, 6, $7,8,9,10 . \mathrm{pH}$ was adjusted by adding $\mathrm{HCl} / \mathrm{NaOH}$. The adsorbent of $0.5 \mathrm{~g} / \mathrm{L}$ was added and then after 30 minutes the supernatant was collected and the final arsenic concentration was determined and the percentage removal of Arsenic was calculated.

\subsection{Determination of Optimum Dosage for Pyrolyzed And Non- Pyrolyzed Almond Shells}

In order to find optimum dosage, the synthetic Arsenic solution having concentration of $5 \mathrm{mg} / \mathrm{L}$ was used, this solution was taken in 1 litre beakers and the $\mathrm{pH}$ of the solution was kept constant i.e., 4 for pyrolysed and 5 for non-pyrolysed Almond shells. Then the adsorbent is added in increasing order of $0.5,1,1.5,2,2.5$, and $3 \mathrm{~g} / \mathrm{L}$ Simultaneously. After 30 minutes, the supernatant was collected to determine the final Arsenic concentration and the percentage removal of arsenic was calculated.

\subsection{Determination of Optimum Contact Time for Pyrolyzed and Non-Pyrolyzed Almond Shells}

In order to find optimum contact time, the synthetic Arsenic solution having concentration of 0.75 $\mathrm{mg} / \mathrm{L}$ was used, this solution was taken in 1 litre beakers and the $\mathrm{pH}$ of the solution was kept constant i.e., 4 for pyrolysed and 5 for non-pyrolysed Almond shells. And then the adsorbent as per the Optimum dosage value was added i.e., $2 \mathrm{~g} / \mathrm{L}$ for pyrolysed and $2.2 \mathrm{~g} / \mathrm{L}$ for non-pyrolysed Almond 
shells. Then the sample was collected at 5 minute interval till desorption occurs to find the final concentration and efficiency removal of arsenic was calculated.

\subsection{Hair Dye Samples}

In this present work, hair dye samples were used to check whether the hair dye samples contains Arsenic or not. Four different types of powdered hair dyes subjected to $\mathrm{pH}$ and Arsenic analysis. Table 1 shows the details of hair dye samples.

\subsubsection{Preparation of Hair dye solution and determination of arsenic}

The four samples was diluted in $100 \mathrm{~mL}$ distilled water, from which $1 \mathrm{~mL}$ is then diluted in $50 \mathrm{~mL}$ distilled water. Then the $1 \mathrm{~mL}$ of hair dye sample is taken from the $50 \mathrm{~mL}$ mixture in nessler's tube add $1 \mathrm{ml}$ of potassium iodate, $1 \mathrm{ml}$ of hydrochloric acid, $1 \mathrm{ml}$ of variamine blue $\mathrm{b}$ solution and $2 \mathrm{ml}$ of sodium acetate solution and make up it the same sample. After $5 \mathrm{~min}$, note down the absorbance for 4 samples prepared at $556 \mathrm{~nm}$.

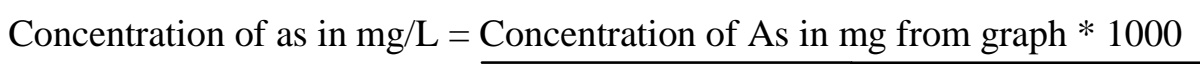

Volume of sample

\subsection{Morphological Study of Pyrolysed and Non Pyrolysed Almond shells}

The morphological characteristics of non pyrolysed and pyrolysed almond shell particle was analysed subjecting to scanning electron microscopy and EDX analysis.

Table1. Details of Hair dye samples considered for analysis

\begin{tabular}{|c|c|c|}
\hline Sample ID & Batch number & Manufacture date \\
\hline Sample 1 & 08 & April 2014 \\
\hline Sample 2 & 46924 & October 2014 \\
\hline Sample 3 & 1720 & December 2014 \\
\hline Sample 4 & 021 & June 2014 \\
\hline
\end{tabular}
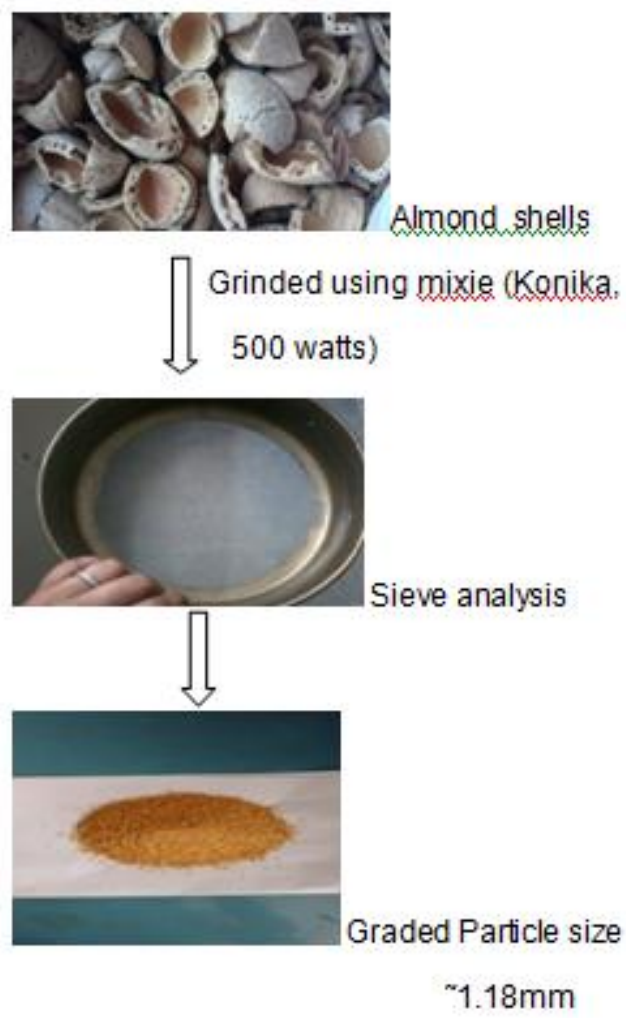

Plate2. Flowsheet of non-pyrolysed almond shells preparation 

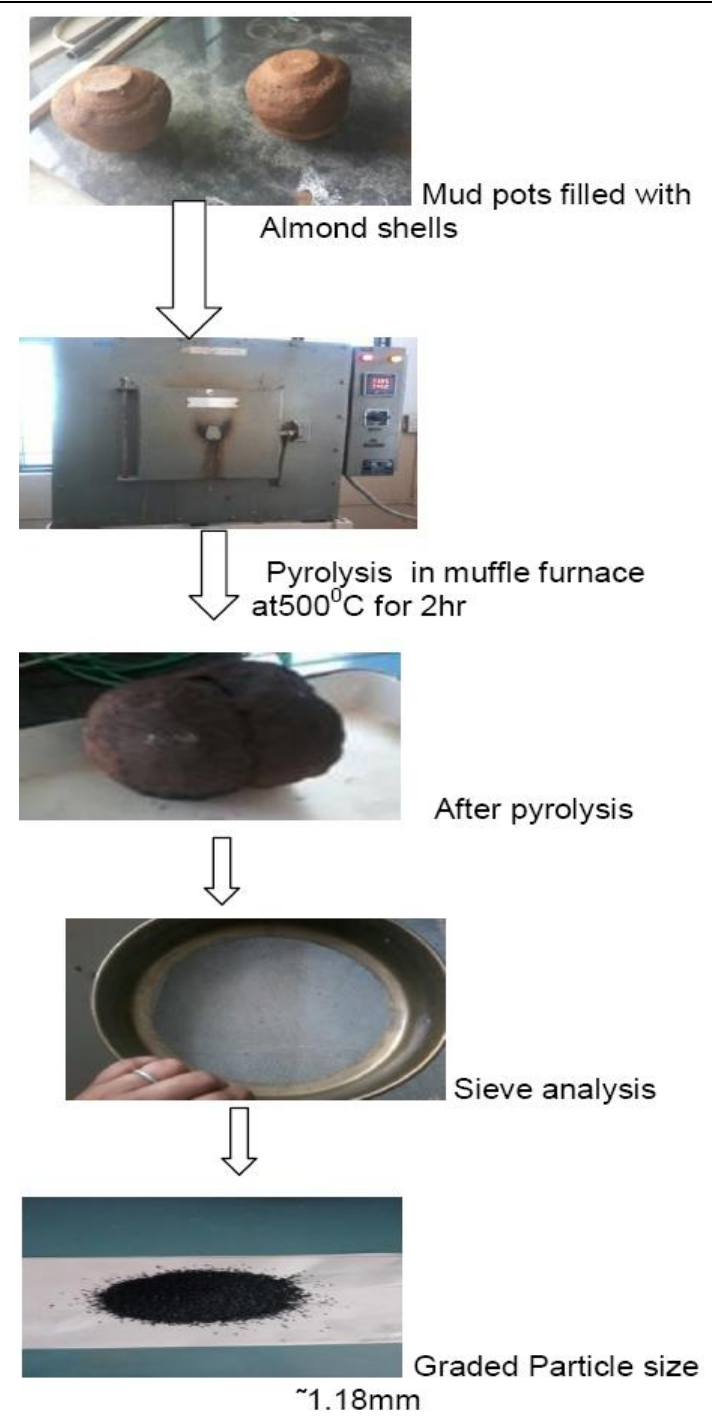

Plate3. Flow sheet of pyrolysed almond shells preparation

\section{RESUlts AND Discussions}

This section deals with the results of optimum conditions.

\subsection{Optimum Conditions for Arsenic Removal Using Synthetic Solution}

Removal of Arsenic species by pyrolysed and non-pyrolysed granule has been studied in the present investigation and the effects of various process parameters such as $\mathrm{pH}$, adsorbent dose, contact time and initial Arsenic concentration are discussed as follows:

The synthetic Arsenic water was prepared by diluting $17 \mathrm{~mL}$ of standard Arsenic solution in $1000 \mathrm{~mL}$ of distilled water. It was observed that the Optimum $\mathrm{pH}$ for non-pyrolysed Almond shells was 5 and for pyrolysed Almond shells was 4. The removal efficiency with respect to $\mathrm{pH}$ is shown in Figure 1.

It was observed that the Optimum dosage for non-pyrolysed Almond shells was $2.2 \mathrm{~g} / \mathrm{L}$ and for pyrolysed Almond shells was $2 \mathrm{~g} / \mathrm{L}$. The removal efficiency with respect to dosage is shown in Figure 2

It was observed that the Optimum contact time for non-pyrolysed Almond shells was 30 minutes and for pyrolysed Almond shells was 25 minutes. The removal efficiency with respect to contact time is shown in Figure 3

\subsubsection{Effect of Optimum $\mathrm{pH}$}

An effect of $\mathrm{pH}$ on the removal of Arsenic for adsorbent is shown in Figure 1. Literature says that $\mathrm{pH}$ plays an important role for the removal of Arsenic from aqueous solution by adsorption. It alters the surface charge of the adsorbent. The effect of $\mathrm{pH}$ on the adsorption could be attributed to several 
mechanisms such as electrostatic interaction, complexation, ion exchange and surface charge on carbon. At $\mathrm{pH}<4$, percent removal of Arsenic increases with the increase in solution $\mathrm{pH}$. Significant improved in percentage removal of Arsenic are observed within the $\mathrm{pH}$ range of 4-5. The highest Arsenic removal of $44 \%$ at $\mathrm{pH} 5$ for non-pyrolised Almond shells and $76 \%$ at $\mathrm{pH} 4$ for pyrolised Almond shells and then decreases considerably with increase in the $\mathrm{pH}$ up to 10 (Naveen dwivedi et al., 2014).

\subsubsection{Effect of Optimum dosage}

An effect of adsorbent dose on the removal of Arsenic as shown in Figure 2. From the figure, it is evident that adsorption is mainly a surface phenomenon, the amount of surface vacant for adsorption and therefore the mass of adsorbent can extensively influence adsorption efficiency. Therefore, the effect of Almond shell dosage on Arsenic removal was investigated and illustrates that the increase in percentage removal of Arsenic in the initial stage is due to the increase in adsorbent concentration. The removal of Arsenic for non-pyrolysed Almond shells at a dose of $2 \mathrm{~g} / \mathrm{L}$ was 2\%; removal improved to $30 \%$ when the almond shell dosage was increased to $2.2 \mathrm{~g} / \mathrm{L}$ and remained almost unchanged thereafter. The removal of Arsenic for pyrolysed at a dosage of $1.5 \mathrm{~g} / \mathrm{L}$ was $23 \%$ and increase upto $42 \%$ at a dosage of $2.5 \mathrm{~g} / \mathrm{L}$.

The above observations can be explained by the fact that with the increase in adsorbent dose, the number of active sites in unit dosage increases, which leads to an increase in the percentage removal of Arsenic. Adsorption processes are exothermic in nature; the extent and the rate of adsorption in most cases decrease with the increase in temperature. At high temperature there is possibility of desorption of Arsenic (Naveen dwivedi et al., 2014).

\subsubsection{Effect of Optimum contact time}

Adsorption experiments were carried out over different contact time for varying pHof Arsenic solution in Figure 5.5. From the time variation experiments, it was observed that the percentage of As (III) adsorption increased with increase in contact time upto 30 minutes. Beyond that there is no further increase in percentage adsorption. So it can be concluded that the equilibrium time for the process is 30 minutes. Further it can be observed that the rate of adsorption was very fast at the initial stage of adsorption and it increases with further increase in time. The faster rate was continued upto 25 minutes for non- pyrolised and 30 minutes for pyrolised Almond shells which shows the efficiency of $66 \%$ and $35 \%$ respectively (S.J Attar et al.,).

\subsection{Arsenic Determination in Hair Dyes}

In this present work, hair dye samples were used to check whether the hair dye samples contains Arsenic or not. Four different types of powdered hair dyes were taken for the analysis and the analysis was conducted in the laboratory for $\mathrm{pH}$ and Arsenic. The $\mathrm{pH}$ of samples was tabulated in Table 2 which is indicating alkaline range. The sample contained considerable amounts of Arsenic which is determined and the initial concentration of arsenic in the hair dye samples are also indicated in Table 2.

From the results, it was observed that sample 4 contains more Arsenic concentration, hence, this work is continued to determine the removal efficiency of Arsenic using Almond shells using sample 4.

\subsection{Removal of Arsenic from Hair Dye Solution}

The Optimum conditions were used to find out the efficiency of Almond shells in Arsenic removal from Hair dye samples shown in Table 3, which shows that the pyrolysed Almond shells was having a removal efficiency of $45 \%$ and non-pyrolysed Almond shells was having a removal efficiency of 43\%.Hence, non-pyrolysed Almond shells can directly used for the treatment process.

Table2. Concentration of Arsenic in hair dye samples

\begin{tabular}{|c|c|c|}
\hline Sample detail & pH & Concentration of As (mg/L) \\
\hline Sample 1 & 9.86 & 6.44 \\
\hline Sample 2 & 9.84 & 11.33 \\
\hline Sample 3 & 10.3 & 7.55 \\
\hline Sample 4 & 9.63 & 17.11 \\
\hline
\end{tabular}


Deekshitha S J et al.

Table3. Efficiency of Almond shells in Arsenic removal from hair dye solution

\begin{tabular}{|c|c|c|c|c|}
\hline SI No. & Almond shells & $\begin{array}{c}\text { Initial concentration } \\
\text { In mg/L }\end{array}$ & $\begin{array}{c}\text { Final concentration } \\
\text { In mg/L }\end{array}$ & $\begin{array}{c}\text { Efficiency } \\
\text { Removal (\%) }\end{array}$ \\
\hline 1 & Pyrolysed & 4.44 & 2.4 & 45 \\
\hline 2 & Non-pyrolysed & 4.44 & 2.53 & 43 \\
\hline
\end{tabular}

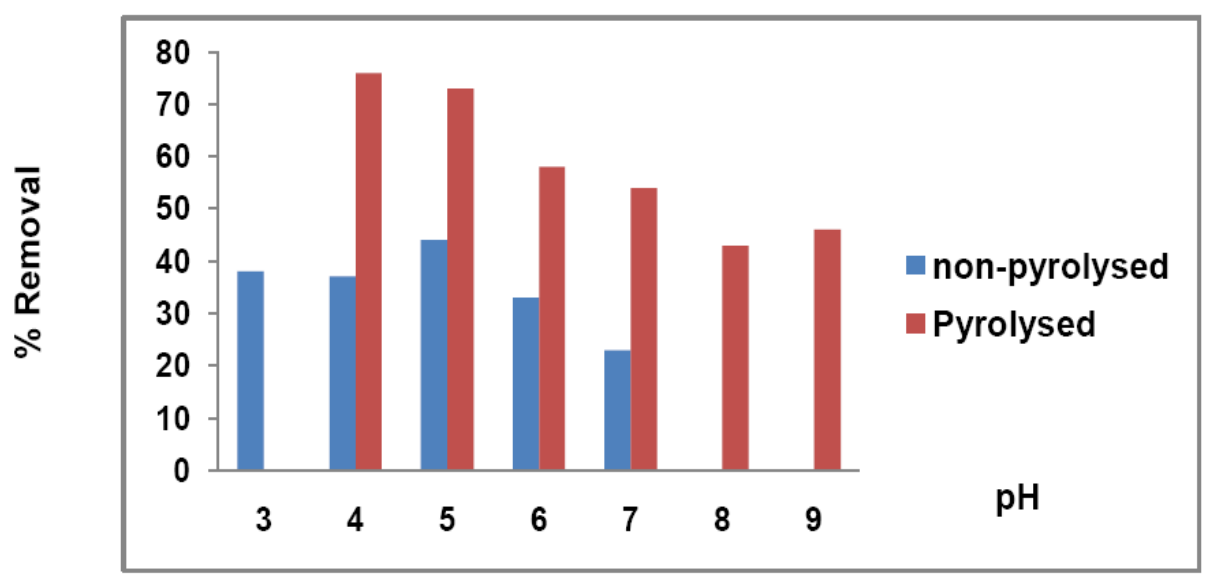

Figure1. Percentage removal of Arsenic for varied $p H$

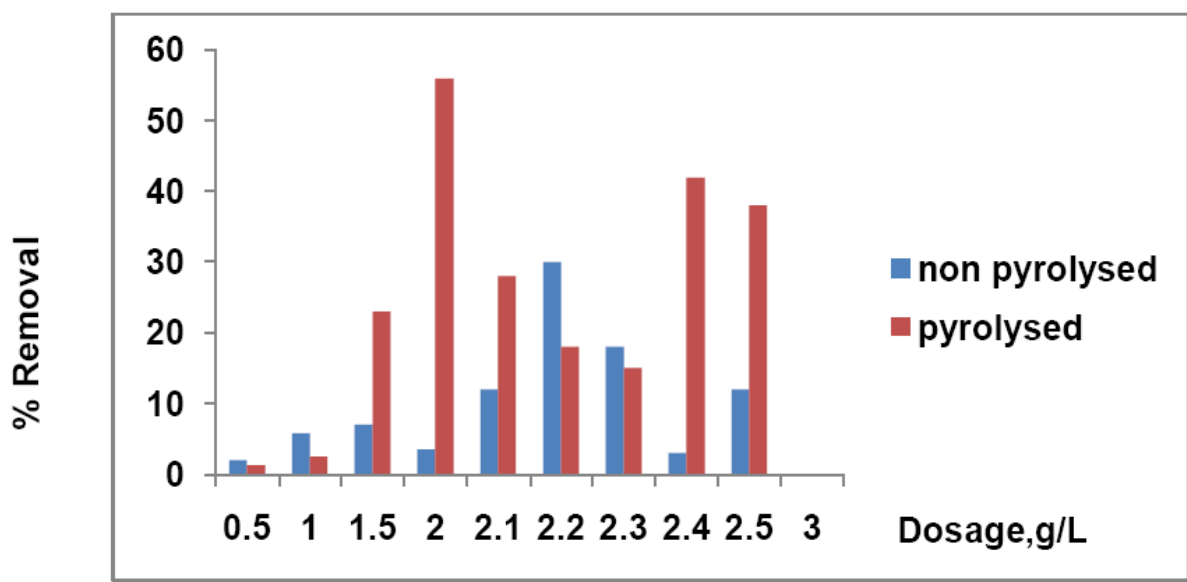

Figure2. Percentage removal of Arsenic for varied Dosage

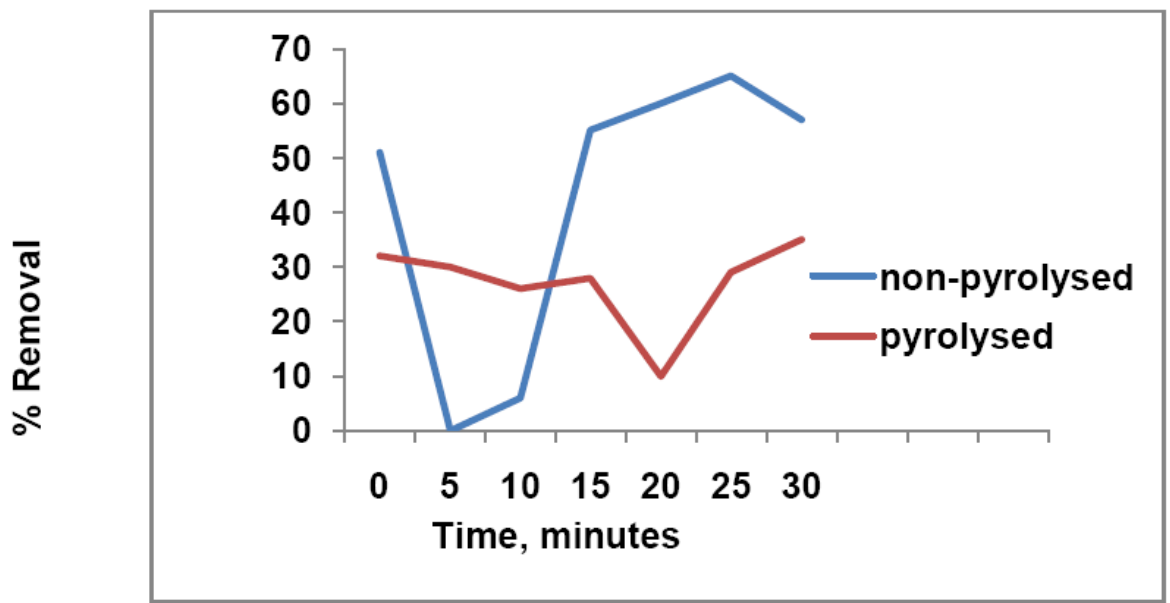

Figure3. Percentage removal of Arsenic for varied contact time

\subsection{Morphological Analysis}

The Figure 6 shows the SEM analysis of unloaded and loaded non-pyrolised Almond shells for different magnification in which the lighter region indicates the non-conductive region which shows accumulation of electrons is more and the darker region shows the conductivity region where the electron accumulation is less. 
TheFigure 7 shows the SEM analysis of unloaded and loaded pyrolised Almond shells for different magnification in which the lighter region indicates the non-conductive region which shows accumulation of electrons is more and the darker region shows the conductivity region where the electron accumulation is less.
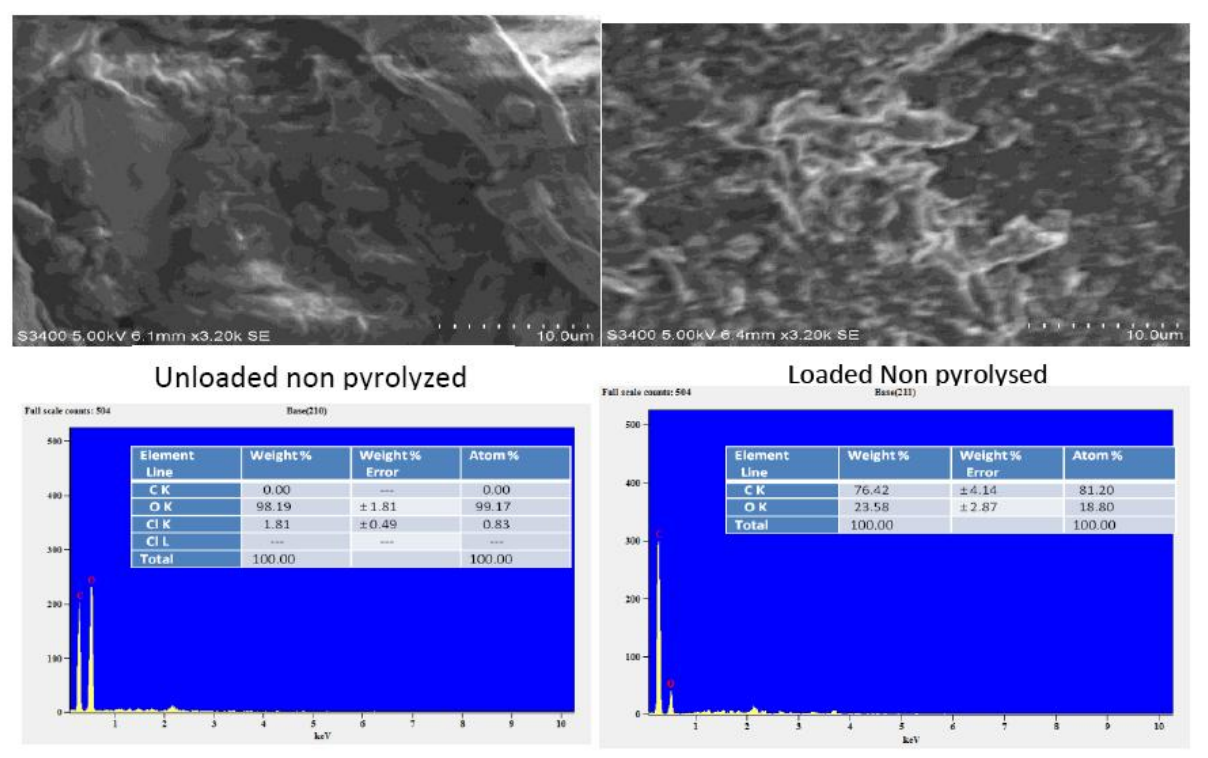

Figure6. SEM with EDX analysis of unloaded and Loaded non-pyrolysed Almond shells
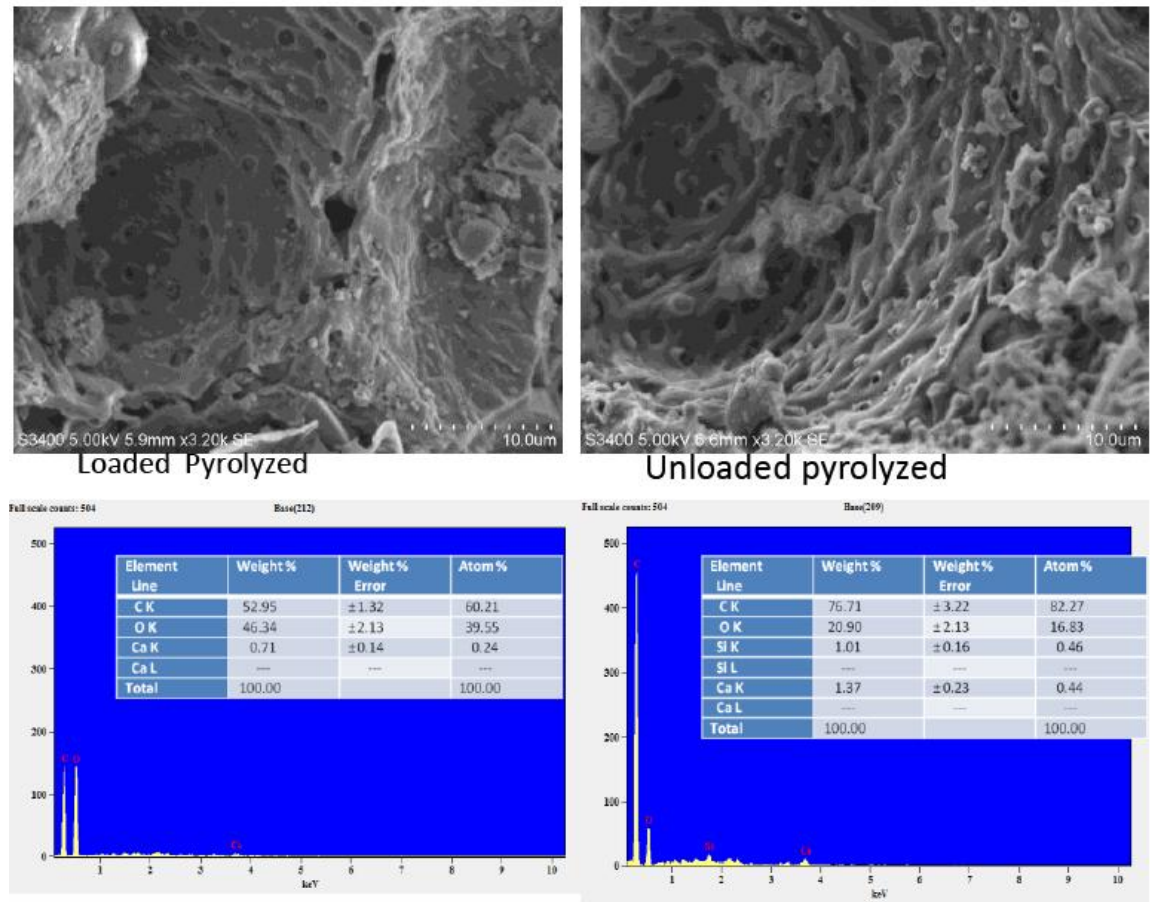

Figure7. SEM with EDX analysis of Unloaded and Loaded Pyrolysed Almond shells

\section{Conclusions}

From this work it can be concluded that,

- Optimum pH for pyrolysed and non-pyrolysed almond shells was found to be 4 and 5 respectively.

- Optimum Dosage for pyrolysed and non-pyrolysed almond shells was found to be 2 and $2.2 \mathrm{~g} / \mathrm{L}$ respectively.

- Optimum contact time for pyrolysed and non-pyrolysed almond shells was found to be 30 mins and 25 mins respectively.

- Efficiency removal of non-pyrolysed and pyrolysed from hair dye solution was found to be $43 \%$ and $45 \%$.

- Almond shells are evaluated as adsorbent for Arsenic removal. 


\section{REFERENCES}

[1] Hajar Nasser, Razankheir-Bek.,2014."Determination of Arsenic(As) in some Environmental Samples Utilizing Potentiometric Titration: Under Modified Analytical and Technical Conditions", International Journal of Pharmacy Research, Volume 3, ISSN: 0975-8216, pp17-26

[2] Naveen Dwivedi, Chandrajit Balomajumder, Prasenjit Mondal.,2014."Study for the treatment of Cyanide Bearing wastewater using Biosorbent PrunusAmygdalus (Almond shell): Effect of pH, adsorbent dose, contact tie, temperature and initial Cyanide concentration", International Research Journal of Environmental Sciences, Volume 3(1), ISSN 2319-1414, pp23-30

[3] Geetha K S, Belagali S L.,2013."Removal of Heavy Metals and Dyes Using Low Cost Adsorbents from Aqueous Medium", IOSR Journal Of Environmental Science Toxicology and Food Technology, Volume 4, Issue 3, pp 56-68

[4] Changwei Zhao, Songshan Du, Tao Wang, Jian Zhang, Zhaokun Luan.,2012.”Arsenic Removal from Drinking Water by Self-Made PMIA Nanofiltration Membrane", Advances in Chemical Engineering and Science, Volume 1, Issue 2, pp366-371

[5] MridulBuragohain, H P Sarma.,2012."A Study on Spatial Distribution of Arsenic in Groundwater Samples of Dhemaji District of Assam, India by Using Arc View GIS Software", Scientific Reviews and Chemical Communications, Volume 2,ISSN 2277-2669, pp7-11

[6] Mosleh M Manfe, S J Attar, M Parande, Niraj S Topare.,2012."Treatment of Cr(VI) Contaminated Wastewater Using BiosorbentPrunusAmygdalus (Almond) nut shell carbon”, International Journal of Chemical Science, ISSN 0972-768X, pp609-618

[7] Neha Chaurasia, Amarnath Mishra, S K Pandey.,2012."'Finger Print of Arsenic Contaminated Water in India-A Review", Forensic Research, Volume 3, Issue 10, pp1-4

[8] M Israt Jahan, M Abdul Motin, M Moniuzzaman M Asadullah.,2008."Arsenic Removal from Water using Activated Carbon obtained from Chemical Activation of Jute Stick", Indian Journal of Chemical Technology, Volume 15, Issue 3, pp413-416

[9] Dinesh Mohan, Charles U Pittman Jr.,2007."Arsenic removal from Water/Wastewater using Adsorbents-A Critical Review", Journal of chemical engineering, Volume 2, Issue 4,pp1-53

[10] Amithva Mukherjee, Mrinalkumar Sengupta.,2006."Arsenic Contamination in Groundwater: A Global Perspective with Emphasis on the Asian Scenario" International Centre for Diarrhocal Disease Research, ISSN 1606-0997, pp 142-163

[11] B Narayana, Tom Cherian, Mendalin Mathew, Chand Pasha.,2006. "Spectrophotometric Determination of Arsenic in Environmental; and Biological samples", Indian Journal of Chemical Technology, Volume 13, pp36-40

[12] Kelly B Payne, Tarek M Abdel- Fattah.,2005."Adsorption of Arsenate and Arsenite by Iron treated Activated Carbon and Zeolites: Effects of $\mathrm{pH}$ Temperature and Ionic Strength", Journal of Environmental Science and Health, Volume 2, ISSN-1093-4529, pp723-749 